\title{
Priming effect of figures that represent external objects or human body parts
}

\author{
Felipe Santos de Oliveira ${ }^{1,3}$, Roberto S. Fraga Filho ${ }^{2,3}$, Elton Hiroshi Matsushima ${ }^{3}$, and Luiz G. \\ Gawryszewski ${ }^{3}$ \\ 1- Universidade Federal do Rio Grande do Norte, Natal, RN, Brazil \\ 2- Universidade Estácio de Sá, Rio de Janeiro, RJ, Brazil \\ 3- Universidade Federal Fluminense, Niterói, RJ, Brazil
}

\begin{abstract}
A visual stimulus (e.g., a letter, word, or object) may have a lasting effect on the processing of subsequent stimuli. The present study verified the priming effect of a figure (i.e., five-petal daisy) on manual reaction time (MRT) to another equal or different five-petal daisy. Two distinct groups were tested. One group was instructed that the five-petal daisy represented a human hand. The other group was instructed that the five-petal daisy represented a flower. The figures in the pairs of stimuli could share or not share some features such as handedness and view. In both groups, after being informed whether the five-petal daisy represented a flower or human hand, an uninformative flower was presented for $200 \mathrm{~ms}$ in the center of the screen. After $1000 \mathrm{~ms}$, a second flower was presented in the same location until the observer responded by pressing a left or right switch. The results showed that prior presentation of the five-petal daisy affected MRT only when the figure represented a human hand. Furthermore, an opposite effect of view on MRT was found. The shorter MRT to the back (dorsal) view of the figure that represented a human hand could be attributable to a faster response to the dorsal view of a hand figure made with a prone posture of the participants' hand than to a front (palm) view. The longer MRT to the back view of the figure that represented a flower may be due to a mental rotation of the object along its vertical axis before selecting the correct response because the response was based on the position of the asymmetrical petal in the canonical front view of the daisy. Keywords: perceptual priming, conceptual priming, manual reaction time, handedness, instructions.
\end{abstract}

Received 6 September 2012; received in revised form 22 January 2013; accepted 14 February 2013. Available online 27 June 2013.

\section{Introduction}

The history of the neuropsychological investigation of memory in either normal humans or patients with amnesia have shown that memory is processed by more than one cognitive system. These studies demonstrated that memory is composed of two separate systems, one that is explicit or declarative and another that is implicit or non-declarative. Declarative memories depend on the integrity of certain brain structures to allow the conscious and intentional recall of facts and events. Even after injuries in these brain

Felipe Santos de Oliveira, Universidade Federal do Rio Grande do Norte, Departamento de Fisiologia, Centro de Biociências, Brazil. Roberto S. Fraga Filho, Universidade Federal Fluminense, Departamento de Neurobiologia, Brazil. Elton Hiroshi Matsushima, Universidade Federal Fluminense, Departamento de Psicologia, Brazil. Luiz G. Gawryszewski, Universidade Federal Fluminense, Programa de Neurociências, Brazil. Correspondence regarding this article should be directed to: Felipe S. de Oliveira, Universidade Federal do Rio Grande do Norte, Departamento de Fisiologia, Centro de Biociências, Cx. Postal 1.511, Lagoa Nova, Natal, RN, CEP: 59078-970, Tel: +55 84 3215-3409, Fax: +55 84 3211-9206, email: deoliveirafs@gmail.com structures, previous experiences may facilitate performance on tasks that do not involve conscious recall. Moreover, distinct experimental approaches have identified several types of non-declarative memories that are processed by different non-conscious mechanisms (Eichenbaum, Yonelinas, \& Ranganath, 2007; Henke, 2010; Schacter, 1992; Wang \& Yonelinas, 2012).

One subtype of non-declarative memories is referred to as priming and corresponds to an implicit (nonconscious) effect caused by the prior presentation of a stimulus (prime) that facilitates (positive priming) or inhibits (negative priming) the processing of a second stimulus (target) (Banks \& Farber, 2003; Henson, 2009; Mayr \& Buchner, 2007; McNamara \& Holbrook, 2003; Schacter, 1987, 1992; Tulving \& Schacter, 1990; Wagner $\&$ Koutstaal, 2002). These effects do not require conscious or intentional recall. They are preserved in patients with amnesia caused by injury in the medial temporal lobe (DiGirolamo \& Posner, 2000; Kolb \& Whishaw, 2003; Schacter, 1987; Schacter, Chiu, \& Ochsner, 1993; Sternberg, 2008; Tulving, Hayman, \& MacDonald, 1991) and occur even under subliminal presentations (Banks \& Farber, 2003; Busnello, Stein, \& Salles, 2008). 
Letters, words, and objects have been the stimuli most used in priming studies. Such stimuli are initially processed in the primary visual cortex and transmitted by the ventral pathway to cortical areas such as the occipitotemporal junction, inferotemporal area, and inferior frontal area (Rosenzweig, Breedlove, \& Leiman, 2002).

Figures that represent body parts are processed by different brain areas (Parsons \& Fox, 1998; Peelen \& Downing, 2007). In tasks that involve recognition of the handedness of hand figures, some motor-related brain areas are activated such as the supplementary motor area, Brodmann's areas 44/46 and 4 in the left hemisphere, Brodmann's areas 6, 7, and 37 in the right hemisphere, and premotor and posterior parietal cortices (De Lange, Hagoort, \& Toni, 2005; Gawryszewski, Silvados-Santos, Santos-Silva, Lameira, \& Pereira Jr., 2007; Lameira, Gawryszewski, \& Pereira Jr., 2006; Lameira, Gawryszewski, Guimaraes-Silva, Ferreira, Vargas, Umiltà, \& Pereira Jr., 2009; Parsons \& Fox, 1998; Vingerhoets, De Lange, Vandemaele, Deblaere, \& Achten, 2002).

In a previous study we investigated the priming effects of drawings of the human hand on manual reaction time (MRT) using depictions of the left and right hand that were presented as a back or palm view (De Oliveira et al., 2010). The results showed that the presentation of a picture of a human hand influenced MRT to the second stimulus. When the response was selected by the laterality (handedness) of the hand depicted, facilitation of the response elicited by the prime occurred when both the prime and target were physically identical and when they differed with regard to view (i.e., palm or back) but had the same laterality.

Additionally, a previous experiment in our laboratory used a five-petal asymmetrical daisy figure that was presented at different orientations in a handedness recognition task (Gawryszewski, Rocha, Silva, Costa, Lameira, Pereira, \& Umiltà, unpublished results). Two groups of volunteers received different instructions. In one group, the subjects were informed that the five-petal daisy represented a flower. In the other group, the subjects were informed that the five-petal daisy represented a hand. If the instructions stated that the daisy represented a hand, then variations in MRTs based on figure orientation in the handedness task were similar to those observed for a real hand figure (Parsons, 1994). In short, longer MRTs were found for figure orientations that depicted biomechanically difficult hand positions. For example, MRTs for the recognition of a right-hand palm view rotated $90^{\circ}$ to the right (i.e., lateral rotation) were longer than when the hand was rotated $90^{\circ}$ to the left (i.e., medial rotation). In contrast, if the daisy represented an external object (a daisy), then the MRT pattern was similar to the one found for the mental rotation of external objects. The MRT increased as the rotation angle increased, with no difference according to the direction of the rotation. These results showed that the way a stimulus is processed by the brain depends on its semantic meaning.

Based on our previous studies that showed that different instructions elicited different perceptual processing of the same stimulus, likely by activating different cortical streams, we used a figure of an external object (a five-petal daisy) as prime and target stimuli in a priming task. Two groups of volunteers were tested. In one group, the subjects were informed that the fivepetal daisy represented a flower. In the other group, the subjects were informed was that the five-petal daisy represented a hand. Our hypothesis was that the priming effect would be different for figures that represented body parts compared with other more commonly used stimuli such as letters, words, or objects.

\section{Methods \\ Participants}

Eighteen volunteers (nine males) aged 18 to 23 years (mean $=20.5$ years, $\mathrm{SD}=1.6$ years) participated in the study. The protocol was approved by the ethics committee of Universidade Federal Fluminense. All subjects provided informed consent. All of the volunteers were naive about the hypothesis of the study. They were right-handed as determined by the Edinburgh inventory (Oldfield, 1971), did not use any drugs, and had not previously participated in experiments that measured MRT.

\section{Apparatus}

The experiment was performed in a dimly lit and soundproof room. A computer using MEL 2.0 software (Micro Experimental Laboratory) presented stimuli on a 20 in. CRT monitor (Samsung Sync Master 20 GLs) and registered MRTs. A forehead and chin rest kept the participant's head $57 \mathrm{~cm}$ from the screen. The volunteers responded by pressing a switch located on the left or right side of their body.

\section{Procedures}

The prime and target stimuli presented to the participants were black and white drawings of a fivepetal daisy $\left(16^{\circ}\right.$ height $\times 9^{\circ}$ width $)$ on a gray background in the center of the screen. Different instructions were given to each of two independent groups of nine participants each, based on distinct semantic meanings of the same figure.

The Hand group was informed that "The figure represents your hand," and the subjects were asked to respond according to the laterality of the target stimulus as if it were their own hand. As shown in Figure 1, the five-petal daisy represented the palm/dorsal view of the right hand (upper figures) or palm/dorsal view of the left hand (lower figures).

The Flower group was informed that "The figure represents a flower." The subjects were also told that the front view of the five-petal daisy was its canonical view, and the position of the asymmetrical petal in this view defined its laterality and should be used for response selection. Thus, in the Flower group, when a back-view daisy was presented as the target, it should be rotated to its canonical view before response selection. 
The volunteers performed a short training block of 32 trials, followed by 320 trials divided into four blocks with 80 trials each. Each trial consisted of two successive stimuli. The first was the prime, and the second was the target. Both stimuli were presented in the center of the screen. The stimuli consisted of a five-petal daisy, with four petals on top of the flower and one asymmetrical petal to the left or right side (Figure 1). The daisy could be presented in a front or back view. The prime duration was $200 \mathrm{~ms}$. After $1000 \mathrm{~ms}$, the target appeared and remained on the screen until the participant's response, which consisted of pressing a left switch in response to a left figure and a right switch in response to a right figure. After the response, the MRT (in milliseconds) or the message "ERROR" or "NO RESPONSE" (for MRTs longer than $1000 \mathrm{~ms}$ ) or "ANTICIPATION" (for MRTs shorter than $100 \mathrm{~ms}$ ) was shown in the center of the screen for $500 \mathrm{~ms}$. A new trial began after a $1000-\mathrm{ms}$ intertrial interval. The prime features (i.e., laterality and view) had no predictive value for the features of the target.

In the Hand group, the participants have to decide whether the figure represented a right or left hand, despite the view. In the Flower group, the participants had to consider the asymmetrical petal of the daisy as seen in the front view to determine whether it was a right or left flower before selecting the correct response. The participants had to fixate on the center of the screen during the task and blink or move their eyes after a manual response to prevent corneal drying.

We defined four experimental conditions according to the laterality and view of the prime and target (Figure 2 ). In the compatible condition, the laterality of the target and prime was equal, but the figures were not necessarily physically identical. Conversely, in the incompatible condition, the laterality of the target and prime was different. The views could also be equal for the prime and target (congruent condition) or different

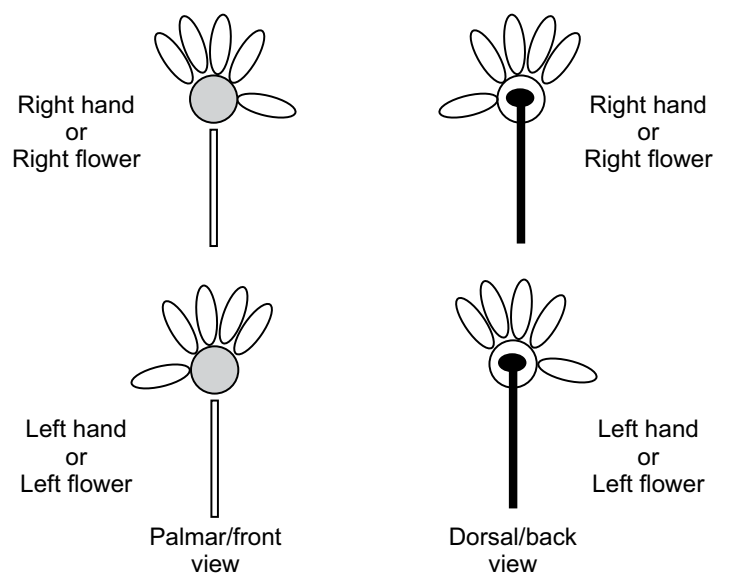

Figure 1. Stimuli used as primes and targets. Two types of instructions ("They represent a hand" or "They represent a flower") were given to classify the figures according to their laterality (right or left) and view (palmar/dorsal for the hand and front/back for the flower). Figure laterality was defined by the asymmetrical petal. In the Hand group, this petal represented a thumb. In the Flower group, the front view of the five-petal daisy was defined as its canonical view, which should be used for response selection.

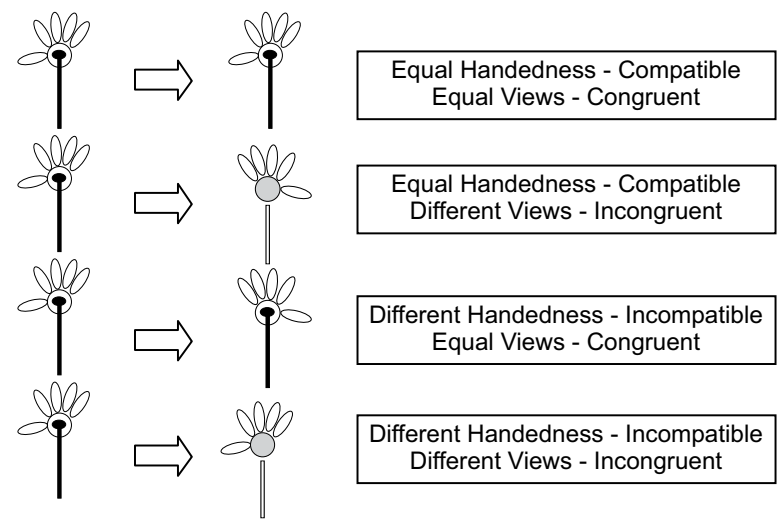

Figure 2. Combinations of a specific prime (back view of a right daisy on the left) and the four possible targets (from top to bottom: back view of a right daisy, front view of a right daisy, back view of a left daisy, and front view of a left daisy). Pressing the right switch was the correct response for the two upper conditions (right hand or flower), and pressing the left switch was the correct response for the two lower conditions (left hand or flower). All of the possible combinations resulted in 16 pairs of primes and targets.

(incongruent condition). Thus, there were 20 trials for each of the 16 pairs of prime and target stimuli.

\section{Statistical analysis}

Separate ANOVAs were run for each group (Flower and Hand) because previous studies showed that body parts and external objects are processed by different cortical pathways, and MRTs for these classes of stimuli are very different. Thus, the magnitudes of the differences between MRTs in the Flower and Hand groups would bias the ANOVA if the between-group factor Instructions was analyzed together. The dependent variable was MRT, and Compatibility, Congruence, and View were the within-subjects factors. Only the individual means of MRTs for correct trials were analyzed. Two participants were excluded because they made more than $10 \%$ errors.

\section{Results}

In the Hand group, only the factors Compatibility $\left(F_{1,8}=18.690, p=.003\right)$ and View $\left(F_{1,8}=7.940, p=\right.$ $.023)$ had significant effects on MRT. MRTs in the compatible condition (i.e., the same laterality for the prime and target; $858 \pm 23.70 \mathrm{~ms}$, mean \pm standard error) were shorter than MRTs in the incompatible condition (i.e., different laterality between the prime and target; $879 \pm 24.95 \mathrm{~ms}$; Figure 3). MRTs for the palm view $(920 \pm 25.59 \mathrm{~ms})$ were longer than MRTs for the back view $(816 \pm 26.29 \mathrm{~ms}$; Figure 4). No significant View $\times$ Laterality interaction was found, indicating that the priming effect occurred when both the prime and target were physically identical (i.e., same laterality and view) and when they had only the same laterality but different views (Figure 2, first and second rows).

In the Flower group, only a significant effect of View was found $\left(F_{1.8}=8.020, p=.022\right)$. The back view (686 \pm $23.88 \mathrm{~ms}$ ) yielded longer MRTs than the front view (616 $\pm 18.10 \mathrm{~ms}$; Figure 5). The longer MRT to the back view 


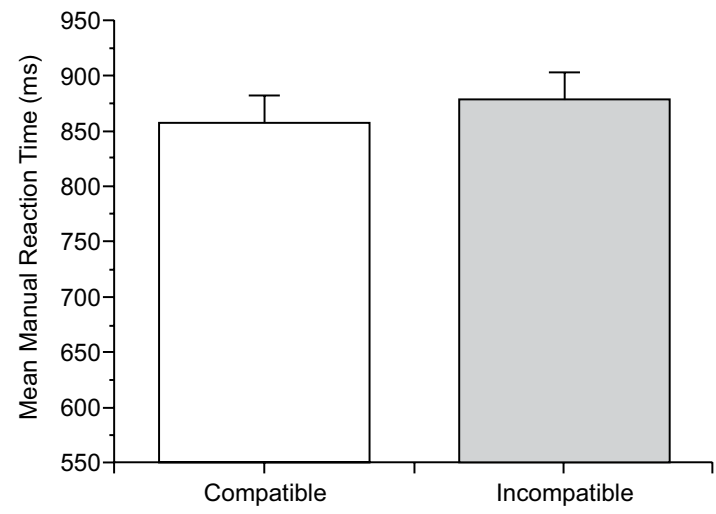

Figure 3. Priming effect due to prime-target compatibility in the Hand group. The MRT was shorter when prime and target had the same laterality (compatible condition) than when their laterality differed (incompatible condition). This effect occurred both for physically identical drawings (same laterality and view) and when the prime and target had opposite views (same laterality but different views). Vertical bars represent the standard error of mean.

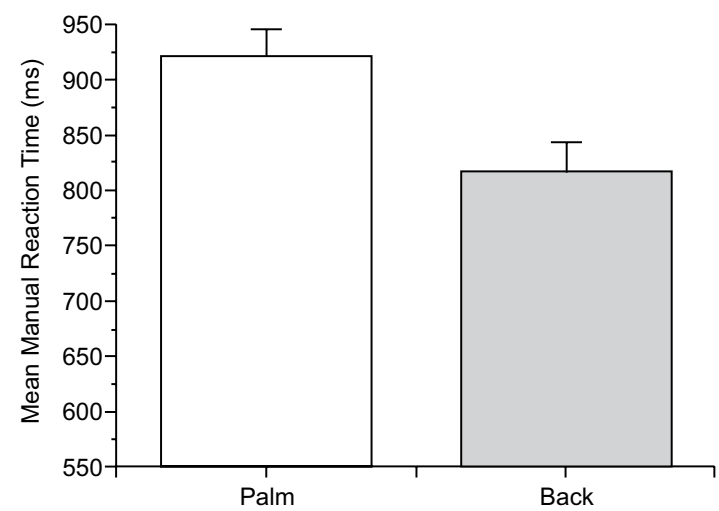

Figure 4. Effect of target view on MRT (ms) in the Hand group. MRT was shorter for drawings that represented the dorsal view of the hand than for drawings that represented the palmar view of the hand. Vertical bars represent the standard error of mean.

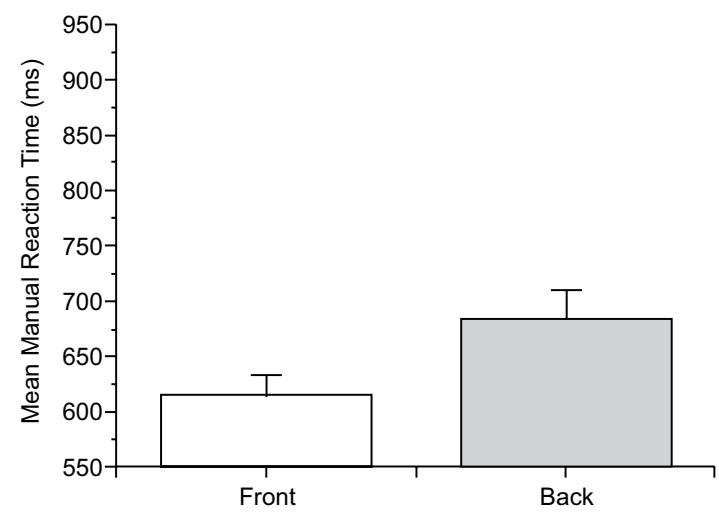

Figure 5. Effect of view on MRT (ms) in the Flower group. The MRT for deciding about the laterality of a flower seen from its back was longer than for a flower seen from its front. The front view was the canonical view that was used to decide flower laterality, and differences in MRT between the views may be due to the time spent rotating the back view to the canonical view. Vertical bars represent the standard error of mean. may be due to a mental rotation of the object along its vertical axis before selecting the correct response because the response was based on the position of the asymmetrical petal in the canonical front view of the daisy.

No other significant main effects on MRT or interactions were found. For example, MRTs were 650 $\pm 124.64 \mathrm{~ms}$ and $652 \pm 138.91 \mathrm{~ms}$ in the Compatible and Incompatible conditions, respectively. Thus, the results showed that the visual features of the prime did not facilitate or inhibit the response to the target.

\section{Discussion}

\section{Effect of compatibility between prime and target}

The main result of the present study was a priming effect in the Hand Group in which an uninformative prime influenced MRT to a subsequent target, facilitating the response to a target that had the same laterality. This result replicates our previous study that used drawings of real hands (De Oliveira et al., 2010) and suggests that the prime activates specific sensorimotor representations in the Hand group, facilitating (in the compatible condition) or inhibiting (in the incompatible condition) the recognition of target laterality. Notably, the physical similarity between the prime and target was not necessary to elicit priming when the response selection was based on target laterality recognition. Thus, one can exclude the possibility that physical similarity is a necessary condition for the occurrence of priming, indicating the occurrence of conceptual priming in which the prime and target are semantically related but not physically identical. Moreover, absence of differences in MRTs between the condition in which the prime and target had the same laterality but were not physically identical and the condition in which they were physically identical indicates that perceptual priming had a minor influence on MRT in the laterality recognition task in the Hand group. Therefore, consistent with our previous work (De Oliveira et al., 2010), facilitation of the laterality recognition of the target may occur if the prime and target share the same laterality, even for a prime that is physically different from the target.

More specifically, our previous study (De Oliveira et al., 2010) indicated that the priming effect in the Hand group is due to the laterality of the prime that subliminally influences the response to the target stimulus. De Oliveira et al. (2010) investigated three groups that used different response criteria in target discrimination tasks. The Handedness group had to consider the handedness of the target (a hand drawing) for response selection (pressing a left or right key). The handedness instruction stated that the figure must be conceived as a body part, thus activating sensorimotor representations that could facilitate (for prime and target stimuli with the same handedness) or inhibit (for prime and target stimuli with different handedness) handedness recognition. The semantic meaning of the handedness concept (left or right hand) affected performance, even with no physical similarities between the prime and 
target based on their different views. In contrast, De Oliveira et al. (2010) found that if response selection was based on view (dorsal or palm view; i.e., a visual feature of the hand that was not related to its laterality in the body), then an interaction between handedness and view was found, and the physical similarity between the prime and target was a necessary condition to produce the priming effect. The similarity between the prime and target facilitated manual responses, likely because of a subliminal effect of physical identity between the first and second stimuli, which is the principle of perceptual priming (De Oliveira et al., 2010). In the third group, the response was a function of the color of the drawing outline. No effect of a black prime on MRT was found. Thus, the presentation of a body part figure per se did not influence the processing of the target when the response was selected by a non-inherent feature of this body part. De Oliveira et al. (2010) suggested that the automatic processing of a prime that represents a body part may have different effects or no effect, depending on the instructions about the feature that should be used to select the correct response.

\section{Effect of view on MRT in the Hand group}

In the Hand group, MRT for handedness recognition when the daisy represented the dorsal view was shorter than when it represented the palm view of a hand. Similar results were observed in the seminal work of Parsons (1994) in tasks that involved handedness recognition, the mental simulation of hand movement, and real hand movement tasks. A possible interpretation of these results is that the faster response to the dorsal view may be due to stronger brain activation when similarity exists between the dorsal view presented on the screen and the participant's posture and view of his hand on the table (for similar hand posture effects, see Lameira, Guimarães-Silva, Ferreira, Lima, Pereira Jr., \& Gawryszewski, 2008a; Lameira et al., 2009). Notably, in this case, the spatial relationship between the asymmetrical petal that represents a thumb and the key response side does not matter. Indeed, for the dorsal view, the thumb points to the side that is opposite to the side of the correct key. The effective correspondence (or absence of correspondence) was actually between the visual input and postural proprioceptive information about the participants' hands. Thus, we suggest that the non-correspondence between posture and palm view prevented a direct comparison between the figure and the participants' own hands, thus slowing their responses.

\section{Effect of view on MRT in the Flower group}

The back view ( $686 \mathrm{~ms}$ ) yielded longer MRTs than the front view $(616 \mathrm{~ms})$. This result may be due to the fact that the front view of the five-petal daisy was defined as its canonical view in the Flower group, which should be used for response selection. Thus, in the Flower group, when a back-view daisy was presented as a target, it should be rotated to its canonical view before the response.

\section{Comparison between the Hand and Flower groups}

We found evidence of conceptual priming in the Hand group but no priming effect in the Flower group. These results suggest that different brain pathways were activated in the two groups.

In addition to the different priming effects in the two groups, comparisons of mean MRTs with Flower instructions $(651 \mathrm{~ms})$ and mean MRTs with Hand instructions $(867 \mathrm{~ms})$ indicated that Flower instructions yielded shorter MRTs than Hand instructions, with a mean difference of approximately $200 \mathrm{~ms}$. This is further evidence that suggests that different cortical processing pathways were activated in the two tasks.

\section{General discussion}

The instructions given to subjects are a variable that provides researchers a means of directing and controlling the mental actions of participants in their experiments (Jack \& Roepstroff, 2002; Woodworth \& Schlosberg, 1965 cited in Dickinson \& Szeligo, 2008). Although several studies have investigated the effects of instructions, most researchers have dedicated little attention to it, often omitting detailed descriptions of the instructions in the Methods sections of their research reports. This triviality ascribed to instructions may be a source for non-replication issues and for some inconsistencies among research findings (Dickinson \& Szeligo, 2008).

The fundamental role of instructions was observed in our previous study (De Oliveira et al., 2010) in which the priming effect of hand figures that were presented in a palm or dorsal view differed according to the criterion used for response selection (handedness or view). When handedness was the criterion, the use of a concept (left or right hand) for selecting the response affected performance in which the priming effect was not dependent on strict physical similarities between the prime and target (same laterality and same view). In contrast, when view was the criterion for response selection, the prime affected MRTs to a second hand figure only when the prime and target were physically identical (same handedness and view), suggesting the occurrence of perceptual priming in this task.

In the present study the effect of the repetition of the laterality and view of a figure that represented either a human hand or flower based on the instructions on MRT was investigated. Although the prime did not provide any information about the following target, it was able to influence MRT to the target in a laterality discrimination task when the drawing represented a hand but not when it represented a flower. Because of the unpredictability of the prime and target relationship, this result could not be attributable to any conscious expectations after the prime. Thus, non-conscious and automatic (i.e., implicit) processes must have been engaged during the laterality recognition task. However, this effect occurred only after the participants were instructed that the stimulus represented a human hand, suggesting that different 
cortical processing pathways were activated in the two groups according to the instructions they received.

Unclear is why no priming effect was found when the instructions stated that the figure represented a flower. In our previous study (De Oliveira et al., 2010), we did not find a priming effect when the prime was a black hand, the target was blue or red, and the criterion for the response was the target's color. Considering these previous results and the results of the present study, we suggest that the priming effect may vary according to the instructions. A prime that represents a hand has a stronger effect on the body part target than an external object prime on an external object target, with no priming effect in the latter condition. Additionally, no priming effect was found when a visual feature of the hand figure (e.g., its color) is used to select the correct response (De Oliveira et al., 2010). These results support the hypothesis that MRTs are shorter and no priming effect is present when the figure represents a flower or the target color is used for response selection. These tasks involve faster cortical pathways and are easier to accomplish than tasks that involve the laterality recognition of a body part, which is processed by slower, more time-consuming cortical processing pathways.

According to the Embodied Neural Theory of Concepts (Gallese \& Lakoff, 2005), the meaning of an action concept is represented in the brain by the same neural pathways and sensory-motor areas involved in the simulation or execution of this action. Considering this theory, neuroimaging investigations have found a somatotopic pattern of activation in cortical motor areas during the observation of actions that involve different parts of the body and during the comprehension of actions reported by language. These findings may suggest a system of mirror neurons (Fernandino \& Iacoboni, 2010).

Our results suggest that the previous presentation of a stimulus that implicitly represents a body part may influence the response to a second stimulus that has the same "body feature." The first stimulus evokes previous motor experiences related to the judgment of laterality of the respective body part. The same effect did not occur when the same task was accomplished with a stimulus that represented a flower. In this task, no activation of motor experiences would influence the response because the response decision is based on only a visual feature (i.e., the asymmetrical petal) and not on the laterality of a body part.

The present results also revealed an effect of view on MRTs in both groups although opposite patterns were found. In the Hand group in which the participants considered the stimulus to be their own hands, the dorsal view of their hand yielded faster responses than the palm view (Lameira, Guimarães-Silva, Ferreira, WerneckGalvão, Pereira Jr, \& Gawryszewski, 2008b; Lameira et al., 2009; Parsons, 1994; Rangel et al., 2010). This effect supports the finding that the amount of time used to determine the laterality of a hand figure is reliably influenced by the actual posture of the responding body part during the task (Jeannerod, 1994; Jeanerod \& Decety, 1995; Lameira et al., 2008a; Lameira et al., 2009; Mercier, Aballea, Vargas, Paillard, \& Sirigu, 2005; Parsons, 1987, 1994; Parsons \& Fox, 1998; Sirigu \& Duhamel, 2001; Vargas, Oliver, Craighero, Fadiga, Duhamel, \& Sirigu, 2004). This effect also supports our previous findings that the response to a dorsal view of a hand figure is faster than the response to a palm view in a laterality judgment made with a prone posture of the participant's hand (Lameira et al., 2008a,b, 2009).

In the Flower group, the front view yielded faster responses than the back view. This effect could be due to the fact that response selection was based on the position of the asymmetrical petal in a front view of the daisy. Thus, if the participants saw the back view of the daisy, then they had to mentally rotate the object along its vertical axis before selecting the correct response.

Importantly, these effects did not correspond to the affordance effect described by Tucker and Ellis (1998) for two reasons (for recent review, see Borghi, Flumini, Natraj, \& Wheaton, 2012): (i) affordance is due to the tendency to accomplish an action toward an object part, and there is no reason to suppose that an asymmetric petal will induce an action to grasp it, and (ii) more importantly, affordance is based on the implicit coding of the object part. In the present task, the asymmetrical petal was explicitly processed before response selection.

In summary, the present results showed that a fivepetal daisy that represented a human hand elicited a priming effect even when the views of the prime and target were different, and the thumb pointed to different sides. A five-petal daisy that represented a flower did not elicit a priming effect. These results suggest that identical figures may activate distinct brain pathways according to their semantic meanings (i.e., body part or external object).

\section{Acknowledgements}

We wish to thank CAPES, CNPq, FAPERJ, PIBICUFF/CNPq, and PROPP - UFF for financial support and to Prof. Antonio Pereira and Prof. Allan Pablo Lameira for their collaborations and support during the study. We would also like to thank Roberto Sena and Maria Luiza Rangel for their help analyzing the data and Prof. Jesus Landeira, Prof. John Araújo, and Prof. Elton Matsushima for serving on the committee that evaluated Felipe's Master's degree dissertation and their helpful comments and insights. We would like to give special thanks to Prof. Luiz G. Gawryszewski for supervision.

\section{References}

Banks, W. P. \& Farber, I. (2003). Consciousness. In A. F. Healy, \& R. W. Proctor (Eds.), Handbook of psychology: Volume 4. Experimental psychology (pp. 11-12). New York: John Wiley.

Borghi, A. M., Flumini, A., Natraj, N., \& Wheaton, L. A. (2012). One hand, two objects: Emergence of affordance in contexts. Brain and Cognition, 80, 64-73.

Busnello, R. H. D., Stein, L. M., \& Salles, J. F. (2008). Efeito de priming de identidade subliminar na decisão lexical com universitários brasileiros. Psico (PUCRS), 39(1), 41-47. 
De Lange, F. P., Hagoort, P., \& Toni, I. (2005). Neural topography and content of movement representations. Journal of Cognitive Neuroscience, 17(1), 97-112.

De Oliveira, F. S., Machado, R. S., Santos Filho, C. A. I., Cunha-Santos, T. P., Pereira, A., Jr., Lameira, A.P., ... Gawryszewski, L.G. (2010). Efeito priming entre figuras de partes do corpo. Psico PUCRS, 4l(1), 118-127.

Dickinson, J. \& Szeligo, F. (2008). Impact of mental operation instructions. Canadian Journal of Experimental Psychology, 62(4), 211-222.

DiGirolamo, G. J. \& Posner, M. I. (2000). Attention. In M. S. Gazzaniga (Ed.), The new cognitive neurosciences, 2nd edition (pp. 622-632). Cambridge: MIT Press.

Eichenbaum, H., Yonelinas, A. P., \& Ranganath, C. (2007). The medial temporal lobe and recognition memory. Annual Review of Neuroscience, 30, 123-152.

Fernandino, L. \& Iacoboni, M. (2010). Are cortical motor maps based on body parts or coordinated actions? Implications for embodied semantics. Brain \& Language, 112(1), 44-53.

Gallese, V. \& Lakoff, G. (2005). The brain's concepts: The role of the sensory-motor system in conceptual knowledge. Cognitive Neuropsychology, 21, 455-479.

Gawryszewski, L. G., Silva-dos-Santos, C. F., Santos-Silva, J. C., Lameira, A. P., \& Pereira, A., Jr. (2007). Mental rotation of anthropoid hands: A chronometric study. Brazilian Journal of Medical and Biological Research, 40, 377-381.

Henke, K. (2010). A model for memory systems based on processing modes rather than consciousness. Nature Reviews Neuroscience, $11,523-532$.

Henson, R. N. (2009). Priming. In L. R. Squire (Ed.), Encyclopedia of neuroscience (pp. 1055-1063). Amsterdam: Elsevier.

Jack, A. I. \& Roepstorff, A. (2002). Introspection and cognitive brain mapping: From stimulus-response to script-report. Trends in Cognitive Sciences, 6(8), 333-339.

Jeannerod, M. (1994). The representing brain: Neural correlates of motor intention and imagery. Behavioral and Brain Sciences, 17, $187-245$.

Jeannerod, M., \& Decety, J. (1995). Mental motor imagery: A window into the representational stages of action. Current Opinion in Neurobiology, 5, 727-732.

Kolb, B., \& Whishaw, I. Q. (2003). Fundamentals of human neuropsychology, 5th edition. New York: Freeman-Worth Press.

Lameira, A. P., Gawryszewski, L. G., \& Pereira, A., Jr. (2006). Neurônios espelho. Psicologia USP, 17(4), 123-133.

Lameira, A. P., Guimarães-Silva, S., Ferreira, F. M., Lima, L. V., Pereira, A., Jr., \& Gawryszewski, L. G. (2008a). Hand posture and motor imagery: A body part recognition study. Revista Brasileira de Fisioterapia, 12(5), 379-385.

Lameira, A. P., Guimarães-Silva, S., Werneck-Galvão, C., Pereira, A., Jr., \& Gawryszewski, L. G. (2008b). Recognition of hand shape drawings on vertical and horizontal display. Psychology \& Neuroscience, 1(1), 35-40.

Lameira, A. P., Gawryszewski, L. G., Guimaraes-Silva, S., Ferreira, F. M., Vargas, C. D., Umiltà, C., \& Pereira, A., Jr. (2009) Hand posture effects on handedness recognition as revealed by the Simon effect. Frontiers in Human Neuroscience, 3, 59.

Mayr, S., \& Buchner, A. (2007). Negative priming as a memory phenomenon: A review of 20 years of negative priming research. Journal of Psychology, 215(1), 35-51.

McNamara, T. P., \& Holbrook, J. B. (2003). Semantic memory and priming. In A. Healy, \& R. W. Proctor (Eds.), Handbook of psychology: Volume 4. Experimental psychology (pp. 447-474). New York: John Wiley.
Mercier, C., Aballea, A., Vargas, C. D., Paillard, J., \& Sirigu, A. (2008). Vision without proprioception modulates corticospinal excitability during hand motor imagery. Cerebral Cortex, 18(2), 272-277.

Oldfield, R. C. (1971). The assessment and analysis of handedness: The Edinburgh inventory. Neuropsychologia, 9, 97-113.

Parsons, L. M. (1987). Imagined spatial transformation of one's hands and feet. Cognitive Psychology, 19, 178-241.

Parsons, L. M. (1994). Temporal and kinematic properties of motor behavior reflected in mentally simulated action. Journal of Experimental Psychology: Human Perception and Performance, 20(4), 709-730.

Parsons, L. M., \& Fox, P. T. (1998). The neural basis of implicit movements used in recognizing hand shape. Cognitive Neuropsychology, 15, 583-615.

Peelen, M. V., \& Downing, P. E. (2007). The neural basis of visual body perception. Nature Reviews Neuroscience, 8(8), 636-648.

Rangel, M. L., Guimarães-Silva, S., Marques, A. L., Riggio, L., Pereira, A., Jr., Lameira, A. P., \& Gawryszewski, L. G. (2010). Left-right judgment of haptic stimuli representing the human hand. Psychology \& Neuroscience, 3(2), 135-140.

Rosenzweig, M. R., Breedlove, S. M., \& Leiman, A. L. (2002). Biological psychology: an introduction to behavioral, cognitive, and clinical neuroscience, 3rd edition. Sunderland: Sinauer Associates.

Schacter, D. L. (1987). Implicit memory: History and current status. Journal of Experimental Psychology: Learning, Memory, and Cognition, 13(3), 501-518.

Schacter, D. L. (1992). Priming and multiple memory systems: Perceptual mechanisms of implicit memory. Journal of Cognitive Neuroscience, 4(3), 244-256.

Schacter, D. L., Chiu, C. Y. P., \& Ochsner, K. N. (1993). Implicit memory: A selective review. Annual Review of Neuroscience, 16, $159-182$

Sirigu, A., \& Duhamel, J. R. (2001). Motor and visual imagery as two complementary and neurally dissociable mental processes. Journal of Cognitive Neuroscience, 13(7), 910-929.

Sternberg, R. J. (2008). Psicologia cognitiva, 4th edition. Porto Alegre: Artmed.

Tucker, M., \& Ellis, R. (1998). On the relations between seen objects and components of potential actions. Journal of Experimental Psychology: Human Perception and Performance, 24, 830-846.

Tulving, E., \& Schacter, D. L. (1990). Priming and human memory systems. Science, 247, 301-306.

Tulving, E., Hayman, C. A. G., \& MacDonald, C. A. (1991). Longlasting perceptual priming and semantic learning in amnesia: A case experiment. Journal of Experimental Psychology: Learning, Memory, and Cognition, 17(4), 595-617.

Vargas, C. D., Oliver, E., Craighero, L., Fadiga, L., Duhamel, J. R., \& Sirigu, A. (2004). The influence of hand posture on corticospinal excitability during motor imagery: A transcranial magnetic stimulation study. Cerebral Cortex, 14, 1200-1206.

Vingerhoets, G., De Lange, F. P., Vandemaele, P., Deblaere, K., \& Achten, E. (2002). Motor imagery in mental rotation: An fMRI study. NeuroImage, 17(3), 1623-1633.

Wagner, A. D., \& Koutstaal, W. (2002). Priming. In V. S. Ramachandran (Ed.), Encyclopedia of the human brain, vol. 4 (pp. 27-46). San Diego: Academic Press.

Wang, W. C. \& Yonelinas, A. P. (2012). Familiarity and conceptual implicit memory: Individual differences and neural correlates. Cognitive Neuroscience, 3(3-4), 213-214.

Woodworth, R. S. \& Schlosberg, H. (1965). Experimental psychology. New York: Holt, Rinehart and Winston. 
